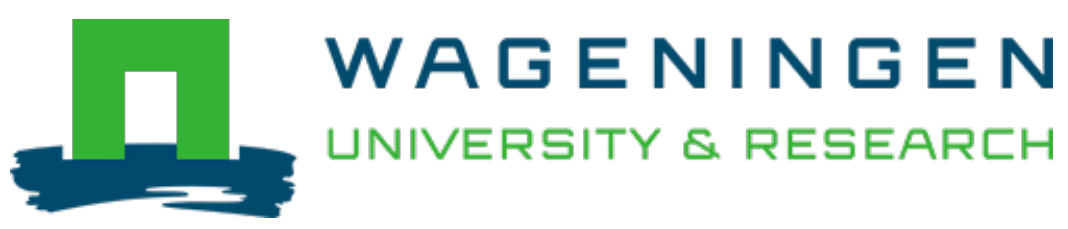

\author{
Insoluble dietary fibre scavenges reactive carbonyl species under simulated \\ physiological conditions : The key role of fibre-bound polyphenols \\ Food Chemistry \\ Zhang, Hao; Troise, Antonio Dario; Qi, Yajing; Wu, Gangcheng; Zhang, Hui et al \\ https://doi.org/10.1016/j.foodchem.2021.129018
}

This article is made publicly available in the institutional repository of Wageningen University and Research, under the terms of article $25 \mathrm{fa}$ of the Dutch Copyright Act, also known as the Amendment Taverne. This has been done with explicit consent by the author.

Article 25 fa states that the author of a short scientific work funded either wholly or partially by Dutch public funds is entitled to make that work publicly available for no consideration following a reasonable period of time after the work was first published, provided that clear reference is made to the source of the first publication of the work.

This publication is distributed under The Association of Universities in the Netherlands (VSNU) 'Article $25 \mathrm{fa}$ implementation' project. In this project research outputs of researchers employed by Dutch Universities that comply with the legal requirements of Article $25 \mathrm{fa}$ of the Dutch Copyright Act are distributed online and free of cost or other barriers in institutional repositories. Research outputs are distributed six months after their first online publication in the original published version and with proper attribution to the source of the original publication.

You are permitted to download and use the publication for personal purposes. All rights remain with the author(s) and / or copyright owner(s) of this work. Any use of the publication or parts of it other than authorised under article $25 \mathrm{fa}$ of the Dutch Copyright act is prohibited. Wageningen University \& Research and the author(s) of this publication shall not be held responsible or liable for any damages resulting from your (re)use of this publication.

For questions regarding the public availability of this article please contact openscience.library@,wur.nl 


\title{
Insoluble dietary fibre scavenges reactive carbonyl species under simulated physiological conditions: The key role of fibre-bound polyphenols
}

\author{
Hao Zhang ${ }^{\text {a,b,c }}$, Antonio Dario Troise ${ }^{\mathrm{d}}$, Yajing Qi ${ }^{\mathrm{e}}$, Gangcheng Wu ${ }^{\mathrm{a}, \mathrm{b}}$, Hui Zhang ${ }^{\mathrm{a}, \mathrm{b}, *}$, \\ Vincenzo Fogliano ${ }^{c}$ \\ a National Engineering Research Center for Functional Food, Jiangnan University, Wuxi 214122, China \\ ${ }^{\mathrm{b}}$ School of Food Science and Technology, Jiangnan University, Wuxi 214122, China \\ ${ }^{\mathrm{c}}$ Food Quality \& Design Group, Wageningen University \& Research, NL-6708 WG, The Netherlands \\ ${ }^{\mathrm{d}}$ Proteomics \& Mass Spectrometry Laboratory, ISPAAM, National Research Council, Naples, Italy \\ e School of Food and Biological Engineering, Jiangsu University, Zhenjiang, Jiangsu Province 212013, PR China
}

\section{A R T I C L E I N F O}

\section{Keywords:}

Insoluble dietary fibre

Bound polyphenols

Reactive carbonyl compounds

Scavenging activity

\begin{abstract}
A B S T R A C T
Polyphenols bound to insoluble fibre may scavenge reactive carbonyl species by surface chemical reactions. In the present study, this hypothesis was tested by investigating the ability of bound-polyphenol rich insoluble dietary fibre (BP-IDF) isolated from blackberry pomace, red cabbage, and wheat bran in scavenging carbonyl compounds. Three BP-IDF showed high scavenging efficacy for glyoxal, methylglyoxal, acrolein and malondialdehyde. Upon in vitro digestion, trapping capacity was retained by the insoluble fraction suggesting that carbonyl trapping activity and physiological relevance needs to be extended to undigestible materials. The removal of bound polyphenols from the polysaccharide backbones through alkaline and acidic treatment reduced by up to $90 \%$ of trapping capacity of BP-IDF. Moreover, methylglyoxal-polyphenol adducts were detected bound to blackberry pomace BP-IDF after hydrolysis. These findings demonstrated that polyphenols bound to IDF scavenged reactive carbonyl species and highlighted the physiological relevance of BP-IDF in limiting carbonyl stress along all the gastrointestinal tract.
\end{abstract}

\section{Introduction}

The gastrointestinal (GI) tract is prone to reactive carbonyl species (RCS) attack as it is constantly exposed to ingested foodstuffs vehicle of thermally and storage induced toxicants. The estimated exposure to unsaturated aldehydes in human is $5 \mathrm{mg} / \mathrm{kg}$ from the consumption of alcoholic beverages, bakery products and cigarette (Wang et al., 2008). Besides, the highly reactive environment of GI tract promotes lipid oxidation during digestion, which leads to the exposure of GI tract to a higher level of oxidation products than tissues and plasma (Wang et al., 2016). Human GI tract thus is repeatedly exposed to carbonyl oxidative threats, which is an important factor of GI inflammatory and neoplastic lesions: increasing evidence show that the abnormal accumulation of RCS, including glyoxal, methylglyoxal, acrolein and malondialdehyde, favours carbonyl stress, promoting modification of tissue protein and DNA, then leading to cell damage cycle in ageing and chronic diseases (Rabbani \& Thornalley, 2015; Wang et al., 2016). Among RCS, glyoxal and methylglyoxal are dicarbonyl compounds constantly formed in the metabolism of carbohydrates and gut microbiota (Ferguson, Tötemeyer, MacLean, \& Booth, 1998; Thornalley, 1985), while acrolein is the simplest $\alpha, \beta$-unsaturated aldehyde and an ubiquitous pollutant existed in the environment and foods. Acrolein can be also generated endogenously through myeloperoxidase, copper-catalysed amine oxidation and gut microbial glycerol metabolism (Zhang, Sturla, Lacroix, \& Schwab, 2018). Malondialdehyde, the major lipid peroxidation product of polyunsaturated fatty acid, is extensively used as biomarker of oxidative damage in several diseases including inflammatory bowel disease and colorectal cancer (Rašić, Rašić, Akšamija, \& Radović, 2018). Therefore, scavenging RCS within GI tract by using polyphenols is crucial to counteract pathological conditions associated with reactive compounds.

Many papers investigated the carbonyl trapping capacity of free polyphenols and aqueous-organic extracts of the foods (Xie \& Chen, 2013) and conjugated RCS metabolites of (-)-epigallocatechin-3-gallate in human faeces have been recently described by Zhang, Zhao, Ohland, Jobin, \& Sang (2019). Furthermore, Jiang et al. (2019) reported that the toxicity of RCS toward Caco-2 cells is decreased after trapping.

\footnotetext{
* Corresponding author at: National Engineering Research Center for Functional Food, Jiangnan University, Wuxi 214122, China.

E-mail addresses: hardyzhang1990@163.com (H. Zhang), Zhanghui@jiangnan.edu.cn (H. Zhang).
} 
Melanoidins are protein-carbohydrates polymers formed during processing and they have RCS trapping activity due to the polyphenols moiety present in their structure as recently described by Zhang, Zhang, Troise, \& Fogliano (2019). Although supramolecular organization of polyphenols in polysaccharides skeleton, the so-called "antioxidant dietary fibre" was extensively described (Saura-Calixto, 1998), the RCS trapping capacity of phenolics bound to insoluble food components, such as dietary fibre, remains unknown. Polyphenols associated to dietary fibre represent approximately $50 \%$ of total dietary antioxidants and are significant building blocks of dietary fibre, accounting for from 1.4 to $50.7 \%$ of the dry weight of insoluble dietary fibre (IDF) in plant foods (Goñi, Díaz-Rubio, Pérez-Jiménez, \& Saura-Calixto, 2009; PérezJiménez, Elena Díaz-Rubio, \& Saura-Calixto, 2015). Antioxidant groups bound to the insoluble fractions have been proved to be still active to quench radicals present in the solvent through surface reaction (Gökmen, Serpen, \& Fogliano, 2009). Other soluble antioxidant compounds can also regenerate this antioxidant capacity, preserving the functional properties of bound polyphenols (Çelik, Gökmen, \& Fogliano, 2013). The whole picture clearly suggests that antioxidant dietary fibre can exert beneficial effects much longer than soluble polyphenols during their survival period in the human GI tract (Pérez-Jiménez, Díaz-Rubio, \& Saura-Calixto, 2013; Vitaglione, Napolitano, \& Fogliano, 2008). Considering a fibre intake recommendation from 19 up to $38 \mathrm{~g}$ per day (Quagliani \& Felt-Gunderson, 2017), it is worth to investigate whether bound-polyphenol rich insoluble dietary fibre (BP-IDF) can efficiently act as an RCS scavenger and exert a physiological relevance modulating the level of RCS inside the gut lumen.
In this study, blackberry pomace, red cabbage and wheat bran, as the representative of fruit, vegetable and cereal, were used to prepare BPIDF with different amounts of bound polyphenols. The carbonyl trapping capacity of these BP-IDF was investigated under simulated physiological conditions to evaluate their potential in controlling the RCS formation within the GI tract. In addition, the removal of bound polyphenols and the identification of putative bound RCS-polyphenol adducts were undertaken to elucidate the possible mechanisms behind trapping process.

\section{Material and methods}

\subsection{Chemicals}

Glyoxal ( $40 \%$ in water, w/v), methylglyoxal ( $40 \%$ in water, $\mathrm{w} / \mathrm{v}$ ), malondialdehyde tetrabutylammonium salt, quinoxaline, 2-methylquinoxaline, $o$-phenylenediamine (OPD), Folin-Ciocalteu reagent, salivary $\alpha$-amylase (100 U/mg), porcine pepsin ( $2500 \mathrm{U} / \mathrm{mg}$ ), porcine pancreatin $(8 \times$ USP), Protease E $(\geq 3.5 \mathrm{U} / \mathrm{mg}$ solid) and Viscozyme L were purchased from Sigma-Aldrich (St. Louis, MO, USA). Thermostable $\alpha$-amylase $(50,000 \mathrm{U} / \mathrm{mL})$, amyloglucosidase from Aspergillus niger $(100,000 \mathrm{U} / \mathrm{mL})$, protease $(50,000 \mathrm{U} / \mathrm{g})$, quercetin, catechin, gallic acid, ferulic acid, caffeic acid, ellagic acid, acrolein (95\%), 2,4-dinitrophenylhydrazine (DNPH), and acrolein-DNPH standard were purchased from Aladdin Reagents Database Inc. (Shanghai, China).

A

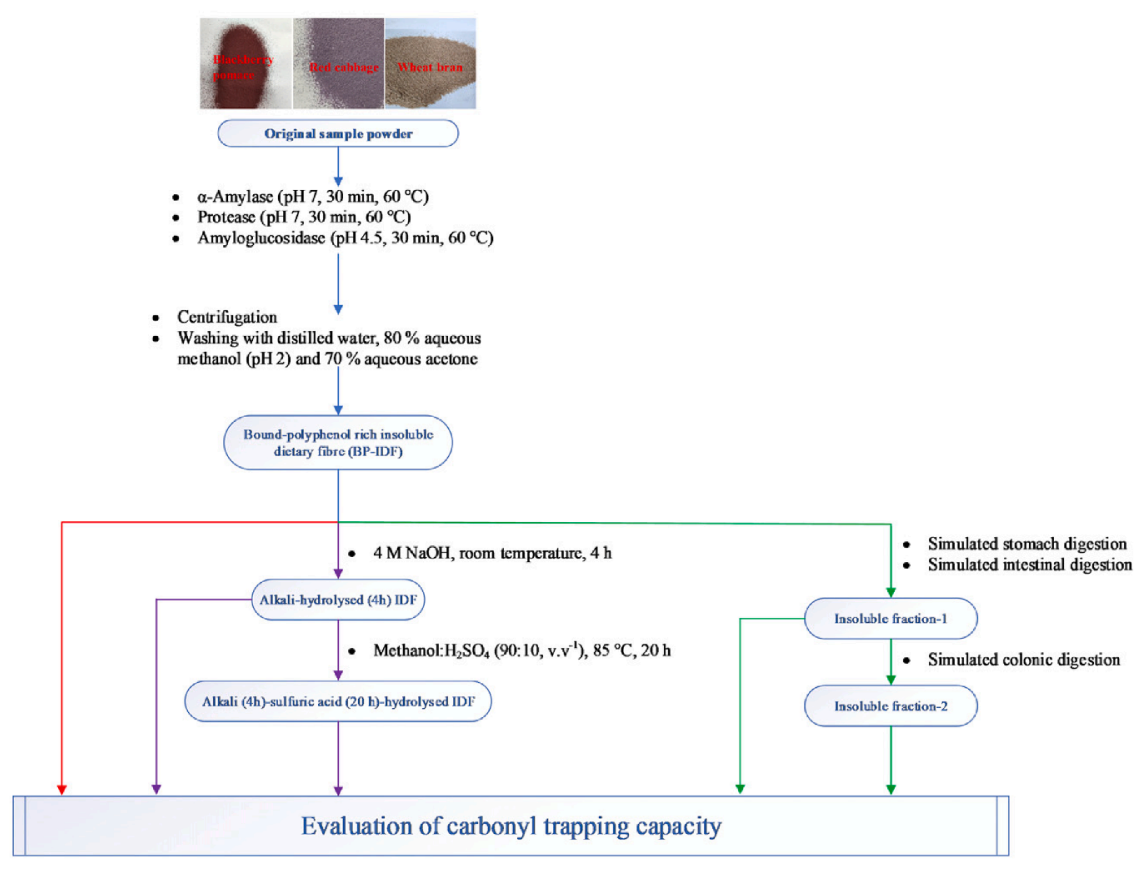

B

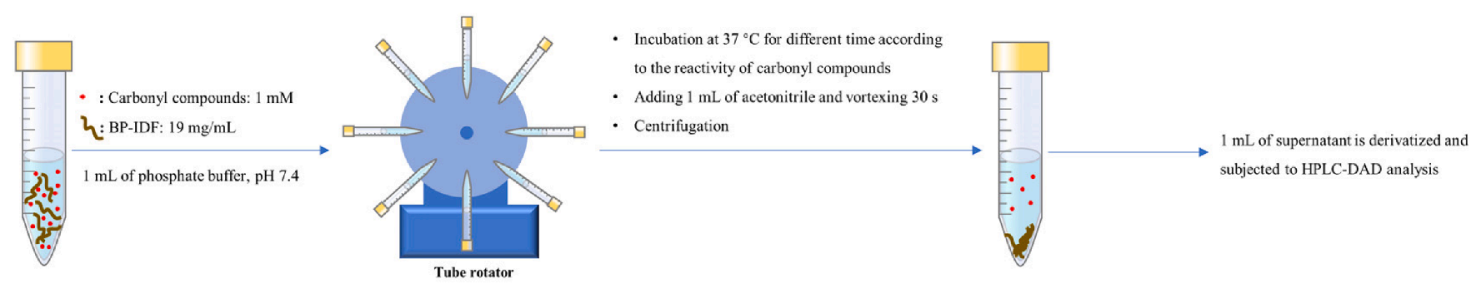

Fig. 1. A: Scheme of preparation of bound-polyphenol rich insoluble dietary fibre (BP-IDF), hydrolysed IDF and the steps of the simulated in vitro digestion process. Red, purple and green lines correspond to Sections 2.3-2.5, respectively. B: Procedure of evaluation of carbonyl trapping capacity. (For interpretation of the references to colour in this figure legend, the reader is referred to the web version of this article.) 


\subsection{Preparation of blackberry pomace, red cabbage and wheat bran BP-} IDF

Red cabbage and blackberry were purchased from a local market. Wheat bran was obtained from Binzhou Zhongyu Food Company Limited (Binzhou, China) and washed to remove physical contaminants. Fresh blackberry was transferred into a cold press juicer to obtain blackberry pomace. After freeze-drying, all of materials were ground in a mill and passed through a $150 \mu \mathrm{m}$ sieve to give original sample powders. BP-IDF was prepared using an established method (Liu et al., 2019) with some modifications (Fig. 1A). Briefly, $200 \mathrm{~g}$ of original sample powder was defatted two times using $2 \mathrm{~L}$ of $n$-hexane. After air-dried overnight, the defatted samples were subjected to sequential enzymatic digestion with $0.3 \% \alpha$-amylase ( $\mathrm{pH} 7$ ), $0.5 \%$ protease ( $\mathrm{pH} 7.5$ ) and $0.2 \%$ amyloglucosidase $(\mathrm{pH} 4.5)$ at $60{ }^{\circ} \mathrm{C}$ for $30 \mathrm{~min}$, respectively. After centrifugation $(3000 \times g, 10 \mathrm{~min})$, the substrate was washed with distilled water, $80 \%$ aqueous methanol $(\mathrm{pH} 2.0$ adjusted by $\mathrm{HCl})$ and $70 \%$ aqueous acetone. The resulting solid residues were freeze-dried and ground to pass through a $150 \mu \mathrm{m}$ sieve to give blackberry pomace, red cabbage and wheat bran BP-IDF, respectively. The yield of blackberry pomace, red cabbage and wheat bran BP-IDF in this experiment was around $31 \%, 33 \%$ and $64 \%$, respectively.

\subsection{Scavenging efficacy studies of RCS by BP-IDF under simulated physiological conditions}

A model reaction system was set up as illustrated in Fig. 1B based on the fibre intake recommendation (38 $\mathrm{g}$ per day) (Quagliani \& FeltGunderson, 2017) and assumed volume of isotonic chyme (2L) reaching the colon each day for healthy people (Hammer, Pruckmayer, Bergmann, Kletter, \& Gangl, 1997). The concentrations of carbonyl compounds used in this model system were selected by taking the estimated daily intake of unsaturated aldehydes and dicarbonyl compounds into account (Degen, Hellwig, \& Henle, 2012; Wang et al., 2008). Briefly, glyoxal (1.0 mM), methylglyoxal (1.0 mM), acrolein $(1.0 \mathrm{mM})$ or malondialdehyde $(0.2 \mathrm{mM})$ were incubated with $19 \mathrm{mg}$ of different BPIDF or cellulose as blank in phosphate buffer $(0.1 \mathrm{M}, \mathrm{pH} 7.4$, final volume $1 \mathrm{~mL}$ ) at $37^{\circ} \mathrm{C}$. The incubation was conducted under a nitrogen atmosphere and dark within a rotating wheel mixer (50 rpm) up to $12 \mathrm{~h}$ for glyoxal, methylglyoxal and malondialdehyde, and $2 \mathrm{~h}$ for acrolein. Each reaction model was incubated in triplicate. After incubation, $1 \mathrm{~mL}$ of acetonitrile was added, and the mixture was vigorously vortexed for $30 \mathrm{~s}$ to extract non-covalent trapped carbonyl compounds and precipitate macromolecules followed by centrifugation at $13,000 \times g$ for 10 min. To detect the remaining glyoxal and methylglyoxal, $1 \mathrm{~mL}$ of supernatant with glyoxal or methylglyoxal was derivatized by $200 \mu \mathrm{L}$ of $0.2 \%$ OPD solution according to our previous method (Zhang et al., 2019) and analysed by HPLC-DAD (Section 2.6). To detect the remaining acrolein and malondialdehyde, $1 \mathrm{~mL}$ of supernatant with acrolein or malondialdehyde was derivatized by adding $20 \mu \mathrm{L}$ of $6 \mathrm{M} \mathrm{HCl}$ and $50 \mu \mathrm{L}$ DNPH solution $(2 \mathrm{mg} / \mathrm{mL}$ in acetonitrile/ $\mathrm{HCl} \mathrm{9:1,} \mathrm{v/v)} \mathrm{at} \mathrm{room} \mathrm{tem-}$ perature for $5 \mathrm{~h}$ and analysed by HPLC-DAD (Section 2.6).

\subsection{Release of bound polyphenols from blackberry pomace, red cabbage and wheat bran BP-IDF}

\subsubsection{Alkaline hydrolysis}

The alkaline treatment of BP-IDF was based on the method by Nardini et al. (2002). Two grams of BP-IDF were treated with $40 \mathrm{~mL}$ of $4 \mathrm{M}$ $\mathrm{NaOH}$ solution containing $10 \mathrm{mM}$ EDTA and 1\% ascorbic acid under a nitrogen atmosphere for $4 \mathrm{~h}$ to release insoluble-bound polyphenols through cleaving ester and ether bonds (Fig. 1A). After hydrolysis and centrifugation, the residue was washed to neutral $\mathrm{pH}$ using distilled water and freeze-dried to give alkali-hydrolysed IDF. The supernatant was acidified to $\mathrm{pH} 2$ with $\mathrm{HCl}(6 \mathrm{M})$ and extracted with $20 \mathrm{~mL}$ of ethyl acetate for six times. The combined extract was dried using a rotary evaporator under vacuum $\left(35^{\circ} \mathrm{C}\right)$ and the dry residue was reconstituted in $4 \mathrm{~mL}$ of $80 \%$ aqueous methanol for the characterization of bound polyphenols (Section 2.7).

\subsubsection{Acidic hydrolysis}

Alkali-hydrolysed IDF was subjected to acidic hydrolysis for the further release of bound polyphenols through cleaving glycosidic bonds according to Arranz \& Saura Calixto (2010). An aliquot of obtained alkali-hydrolysed IDF was treated by $10 \mathrm{~mL}$ of methanol: sulfuric acid solution $(90: 10, \mathrm{v} / \mathrm{v})$ at $85{ }^{\circ} \mathrm{C}$ up to $20 \mathrm{~h}$. The mixture was centrifuged and the residue was washed to neutral $\mathrm{pH}$ followed by freeze-drying to give alkali-sulfuric acid-hydrolysed IDF. Both resulting IDF were subjected to evaluation of carbonyl scavenging capacity as described above (Section 2.3).

\subsection{In vitro digestion of blackberry pomace, red cabbage and wheat bran BP-IDF}

To investigate the effect of gastrointestinal digestion on the carbonyl scavenging ability of BP-IDF, they were subjected to the in vitro digestion process. The in vitro digestion procedure was conducted following the published method (Hamzalıoğlu \& Gökmen, 2016) with some modifications. Simulated salivary fluid (SSF), gastric fluid (SGF) and intestinal fluid (SIF) were prepared to mimic the conditions of the gastrointestinal tract and the compositions of digestion fluids were shown in Table S1. Five grams of BP-IDF were mixed with $10 \mathrm{~mL}$ of SSF and incubated in a water bath with shaking at $37{ }^{\circ} \mathrm{C}$ for $2 \mathrm{~min}$. For stomach digestion, 10 $\mathrm{mL}$ of SGF was added to the mixture and the $\mathrm{pH}$ was adjusted to 3.0 by 6 $\mathrm{M} \mathrm{HCl}$. Then $5 \mathrm{~mL}$ of pepsin solution $(1.25 \mathrm{mg} / \mathrm{mL})$ was added to the acidified mixture and shaken in the water bath at $200 \mathrm{rpm}$ and $37{ }^{\circ} \mathrm{C}$ for $2 \mathrm{~h}$. After the gastric phase the $\mathrm{pH}$ was brought up to 7.0 using $4 \mathrm{M}$ $\mathrm{NaOH}$, and then $20 \mathrm{~mL}$ of SIF containing bile salts $(100 \mathrm{mg} / \mathrm{mL})$ and 5 $\mathrm{mL}$ of pancreatin solution $(5 \mathrm{mg} / \mathrm{mL})$ were added to the gastric chime solution. After saturation with nitrogen to remove oxygen, the mixture was incubated at $37{ }^{\circ} \mathrm{C}$ with shaking for $2 \mathrm{~h}$ to simulate the duodenal phase. Finally, the mixture was first treated with $5 \mathrm{~mL}$ of Protease $\mathrm{E}$ solution $(1.0 \mathrm{mg} / \mathrm{mL}, \mathrm{pH} 8.0)$ at $37^{\circ} \mathrm{C}$ for $1 \mathrm{~h}$, and then with $150 \mu \mathrm{L}$ of Viscozyme $\mathrm{L}$ at $37^{\circ} \mathrm{C}$ for $16 \mathrm{~h}$ (pH 4.0) under stirring to simulate colonic digestion process. To obtain insoluble fractions (Fig. 1A), the digested meal after duodenal and colon phase was collected, respectively, and filtered through a paper filter (Whatman 595). The solid residue was washed several times using distilled water and freeze-dried. The resultant insoluble fractions were submitted to the evaluation of carbonyl scavenging capacity as described above (Section 2.3). Each sample was prepared in triplicate. To compare the carbonyl trapping ability of BPIDF after digestion process with other dietary food components, catechin $(0.2 \mathrm{mg} / \mathrm{mL})$ and caffeic acid $(0.3 \mathrm{mg} / \mathrm{mL})$ were selected as the representative of free flavonoids and phenolic acids. The doses used for these components were based on the ratio of their estimated dietary intake to that of fibre (Bo' et al., 2019).

\subsection{Determination of $O P D / D N P H$-Derivatives by $H P L C-D A D$}

Determination of OPD/DNPH derivatives was performed on a Shimadzu Prominence LC-20A Modular HPLC system (Shimadzu, Kyoto, Japan). Separation was achieved using an Agilent Poroshell 120 SB-AQ C18 column $(100 \mathrm{~mm} \times 3.0 \mathrm{~mm}, 2.7 \mu \mathrm{m})$ at a flow rate of $0.4 \mathrm{~mL} / \mathrm{min}$ and $40{ }^{\circ} \mathrm{C}$. A gradient elution program was used as follows (A, $0.1 \%$ aqueous formic acid; $\mathrm{B}, 0.1 \%$ formic acid in acetonitrile): $0 \mathrm{~min}, 10 \% \mathrm{~B}$; $10 \mathrm{~min}, 23 \% \mathrm{~B}$; $20 \mathrm{~min}, 45 \% \mathrm{~B}$; $30 \mathrm{~min}, 70 \% \mathrm{~B}$; $35 \mathrm{~min}, 90 \% \mathrm{~B}$; followed by a re-equilibration step. The injection volume was $5 \mu \mathrm{L}$ and chromatograms were recorded at $315 \mathrm{~nm}$ for quinoxaline derivatives, 310 $\mathrm{nm}$ for malondialdehyde-DNPH derivative and $370 \mathrm{~nm}$ for acroleinDNPH derivative. The remaining glyoxal, methylglyoxal and acrolein in different samples was quantified based on their corresponding standard curve (0.01 $\mathrm{mM}$ to $1.0 \mathrm{mM}$ ) with linearity higher than 0.99 for all 
the investigated compounds. Working solutions of malondialdehyde in the concentration range between $0.01 \mathrm{mM}$ and $0.2 \mathrm{mM}$ were derivatized as described above to establish its external calibration curve. Trapping capacity for each RCS was calculated using the equation (Eq. (1)) as below:

Trapping capacity $(\%)=\frac{\text { amount of RCS in blank }- \text { amount of RCS in samples }}{\text { amount of RCS in blank }}$ $\times 100 \%$

\subsection{Characterization of fibre-bound polyphenols by UPLC-PDA-QTOF- MS/MS analysis}

Bound polyphenols of IDF extracted by alkaline hydrolysis was characterized using a Waters Acquity ultraperformance liquid chromatography (UPLC) system coupled to a photodiode array detector and a Xevo-G2-S quadrupole time-of-flight mass spectrometer (QTOF-MS, Waters, Milford, MA). The separation was performed on a Poroshell 120 SB-AQ C18 column (Agilent) using $0.1 \%$ aqueous formic acid (solvent A) and $0.1 \%$ formic acid in acetonitrile (solvent $\mathrm{B}$ ). The gradient elution was used at a flow rate of $0.4 \mathrm{~mL} / \mathrm{min}: 0 \mathrm{~min}, 5 \% \mathrm{~B} ; 10 \mathrm{~min}, 15 \% \mathrm{~B} ; 20$ $\mathrm{min}, 30 \% \mathrm{~B} ; 30 \mathrm{~min}, 70 \% \mathrm{~B} ; 35 \mathrm{~min}, 90 \% \mathrm{~B}$. The column temperature was $35{ }^{\circ} \mathrm{C}$ and the injection volume was $5 \mu \mathrm{L}$. UV-vis signals were recorded on-line with the wavelength range of $200-600 \mathrm{~nm}$. The major operating parameters for the Q-TOF-MS were set as follows: negative ion mode; capillary voltage $3.5 \mathrm{kV}$; cone voltage $30 \mathrm{~V}$; source temperature $120{ }^{\circ} \mathrm{C}$; desolvation temperature $400{ }^{\circ} \mathrm{C}$; desolvation gas and cone gas were set to 700 and $50 \mathrm{~L} / \mathrm{h}$. Centroid mode data were acquired using a multiplexed MS/MS acquisition with alternating low and high energy acquisition $\left(\mathrm{MS}^{\mathrm{E}}\right.$ ), from $\mathrm{m} / \mathrm{z} 50$ to 1500 . MS/MS experiments were performed by using argon as a collision gas and product ions were screened by using collision energy ranging from 25 to $30 \mathrm{eV}$. Mass chromatogram and mass spectral data were collected and processed by MassLynx version 4.1 (Waters). Caffeic acid, sinapic acid, ferulic acid, gallic acid, ellagic acid, catechin and quercetin were identified by comparison of the retention times and $[\mathrm{M}-\mathrm{H}]^{-}$ion mass with their corresponding commercial standards. Other polyphenols were identified by comparison of their $[\mathrm{M}-\mathrm{H}]^{-}$ion mass, $\mathrm{MS}^{2}$ spectra, UV-visible spectrum and retention times with previous reports, especially in blackberry, red cabbage and wheat bran (Arranz \& Saura Calixto, 2010; Ayoub, De Camargo, \& Shahidi, 2016; Mizgier et al., 2016).

UV-vis signals were used for relative quantification based on the calibration curve of standards for each class of polyphenols (PérezRamírez, Reynoso-Camacho, Saura-Calixto, \& Pérez-Jiménez, 2018). Flavanols and hydroxybenzoic acids were monitored at $280 \mathrm{~nm}$ and quantitated with catechin and gallic acid, respectively; hydroxycinnamic acids and ellagitannins were monitored at $320 \mathrm{~nm}$ and quantitated with ferulic acid and ellagic acid, respectively; flavonols were monitored at $365 \mathrm{~nm}$ and quantitated with quercetin.

\subsection{Analysis of the bound methylglyoxal-polyphenol adducts in the blackberry pomace BP-IDF-methylglyoxal system by UPLC-MS/MS}

To obtain mass spectrometry information of fibre-bound adduct of methylglyoxal-polyphenol, $100 \mathrm{mg}$ of blackberry pomace IDF was incubated with methylglyoxal $(1.0 \mathrm{mM})$ in $10 \mathrm{~mL}$ of phosphate buffer $\left(\mathrm{pH} 7.4,0.1 \mathrm{M}\right.$ ) at $37^{\circ} \mathrm{C}$ for $12 \mathrm{~h}$. After incubation, the sample was mixed thoroughly with $10 \mathrm{~mL}$ of acetonitrile and centrifuged at $10,000 \times g$ for $15 \mathrm{~min}$. The resultant residue was subjected to alkaline hydrolysis for $2 \mathrm{~h}$ as described above. The hydrolysate was acidified to $\mathrm{pH} 2.0$ and extracted with ethyl acetate for six times. The combined extract was dried using a rotary evaporator under vacuum $\left(35^{\circ} \mathrm{C}\right)$ and the dry residue was reconstituted in $4 \mathrm{~mL}$ of $80 \%$ aqueous methanol for UPLC-MC/ MS analysis. To prepare the conjugated samples of methylglyoxal with the major bound polyphenols of blackberry pomace BP-IDF, gallic acid, quercetin and catechin $(0.5 \mathrm{mM})$ was incubated with methylglyoxal $(0.5 \mathrm{mM})$ in phosphate buffer $(\mathrm{pH} 7.4,0.1 \mathrm{M})$ at $37^{\circ} \mathrm{C}$ for $4 \mathrm{~h}$, respectively. After incubation, the adducts were directly characterized by UPLC-MS/MS.

The methylglyoxal-polyphenol adducts were identified under the same chromatographic conditions with those of phenolic qualitative analysis but using a TQD triple quadrupole mass spectrometer as detector (Waters, Milford, MA). Negative electrospray ionization was used with the capillary voltage at $3.0 \mathrm{kV}$. Desolvation gas and cone gas were set at 600 and $50 \mathrm{~L} / \mathrm{h}$, respectively. The molecular ions of possible methylglyoxal-polyphenol adducts formed in chemical reaction models were identified in preliminary trials; different channels were used under selected ion monitoring (SIM) mode: $m / z 169$ for gallic acid, $m / z 241$ for mono-methylglyoxal-gallic acid, $m / z 289$ for catechin, $m / z 361$ for mono-methylglyoxal-catechin, $\mathrm{m} / z 433$ for di-methylglyoxal-catechin, $m / z 301$ for quercetin, $m / z 373$ for mono-methylglyoxal-quercetin, $m$ / z 455 for di-methylglyoxal-quercetin. Structural information on three polyphenols and their major methylglyoxal adducts was obtained by product ion scan with $25 \mathrm{eV}$ collision energy. The mass range was set from $m / z 100-500$, and data were acquired and processed with MassLynx version 4.1 (Waters).

\subsection{Statistical analysis}

All analyses were performed in triplicate. Tukey's HSD test was used to determine significant differences between means at the level of $p<$ 0.05 using the IBM SPSS Statistics 23 (IBM Corp., NY, USA).

\section{Results and discussion}

\subsection{Bound phenolic compounds profile of BP-IDF by UPLC-PDA-QTOF analysis}

Fibre-bound phenolic compounds extracted by alkaline hydrolysis were characterized and quantified as shown in Table 1 and the typical UPLC chromatograms at 280, 320 and $365 \mathrm{~nm}$ are presented in Figures S1-S3. The total amount of bound phenolic compounds in alkaline extract of blackberry pomace BP-IDF was $1044.0 \mathrm{mg} / 100 \mathrm{~g}$ DW (dry weight) with 12 polyphenols identified. Ellagitannins accounted for about $43 \%$ of the bound polyphenols in alkaline extract followed by phenolic acids (32.2\%) and flavonoids (24.8\%). Ellagitannins fraction consisted of ellagic acid and sanguisorbic acid dilactone, while gallic acid and caffeic acid gave the major phenolic acids contribution. Regarding flavonoids, five compounds were identified in the alkaline hydrolysate of blackberry pomace BP-IDF, mainly catechin and quercetin. The bound polyphenol composition of blackberry pomace BP-IDF is in line with previous findings reported by Ayoub, De Camargo, \& Shahidi (2016): the most abundant bound phenolic compounds in blackberry seed meals are gallic acid, catechin, quercetin and their derivatives. Additionally, it is important to mention that the alkali hydrolysis required for the release of bound polyphenols from macromolecules may also degrade some of the original phenolic structures. Indeed, sanguisorbic acid dilactone and ellagic acid were generated from the degradation of blackberries ellagitannins through strong chemical hydrolysis (Macierzyński, Sójka, Kosmala, \& Karlińska, 2020).

In red cabbage BP-IDF, a total of 9 phenolic acids and one ellagitannin were found in its alkaline extract. The most abundant phenolic acid was sinapic acid (372.1 mg/100 g DW), followed by $p$-coumaric acid (88.5 mg/100 g DW) and ferulic acid (74.8 mg/100 g DW), while the contents of other phenolic acids ranged from 3.5 to $11.6 \mathrm{mg} / 100 \mathrm{~g}$ DW. Mizgier et al. (2016) also found that hydroxycinnamic acid derivatives are the dominant bound phenolic compounds in red cabbage and mainly include residues of sinapic, $p$-coumaric acid and ferulic acid. Low amount of hydroxycinnamic acid derivatives detected in present study could be a consequence of the strongly alkaline treatment.

Looking at wheat bran BP-IDF, a total of nine different compounds 
Table 1

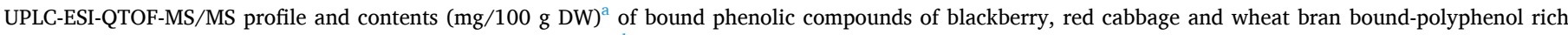
insoluble dietary fibre (BP-IDF) extracted by alkaline hydrolysis. ${ }^{\mathrm{b}}$.

\begin{tabular}{|c|c|c|c|c|c|c|c|}
\hline Peak no. & Proposed compound & $t_{R}(\min )$ & {$[\mathrm{M}-\mathrm{H}]^{-}(m / z)$} & MS/MS ion $(m / z)$ & Blackberry pomace & Red cabbage & Wheat bran \\
\hline \multicolumn{8}{|c|}{ Phenolic acids } \\
\hline 1 & Gallic acid & 2.65 & 169.0083 & 125 & $174.9 \pm 6.3$ & $5.3 \pm 0.2$ & n.d. \\
\hline 2 & $p$-Coumaric acid glucoside & 3.32 & 325.0963 & 163,119 & n.d. & $3.5 \pm 0.1$ & n.d. \\
\hline 3 & Protocatechuic acid & 3.80 & 153.0347 & 109 & $25.7 \pm 1.1$ & $5.2 \pm 0.3$ & $6.9 \pm 0.3$ \\
\hline 4 & Ferulic acid 4-O-glucoside & 5.52 & 355.1050 & 193,134 & n.d. & $6.7 \pm 0.2$ & n.d. \\
\hline 5 & Salicylic acid & 5.68 & 137.0201 & 93 & n.d. & n.d. & $1.3 \pm 0.1$ \\
\hline 6 & Vanillic acid & 7.17 & 167.0617 & 108 & n.d. & n.d. & $3.6 \pm 0.2$ \\
\hline 7 & Caffeic acid & 7.65 & 179.0352 & 135 & $119.7 \pm 4.8$ & $8.1 \pm 0.2$ & $11.5 \pm 0.4$ \\
\hline 8 & Sinapoyl D-glucoside & 7.94 & 385.1145 & 223 & n.d. & $7.4 \pm 0.1$ & n.d. \\
\hline 9 & 5-methoxysalicylic acid & 8.73 & 167.1201 & 108 & n.d. & n.d. & $3.4 \pm 0.2$ \\
\hline 10 & 3,4-dihydroxyphenylaceticacid & 9.66 & 167.0216 & 123 & n.d. & $11.6 \pm 0.5$ & n.d. \\
\hline 11 & $p$-coumaric acid & 10.53 & 163.0378 & 119 & $4.3 \pm 0.1$ & $84.5 \pm 2.1$ & $12.2 \pm 0.3$ \\
\hline 12 & Ferulic acid & 12.18 & 193.0498 & 178,134 & $11.8 \pm 0.4$ & $74.8 \pm 1.2$ & $412.3 \pm 8.4$ \\
\hline 13 & Sinapic acid & 13.25 & 233.0594 & $208,164,149$ & n.d. & $372.1 \pm 7.8$ & $16.4 \pm 0.2$ \\
\hline \multicolumn{8}{|c|}{ Flavonoids } \\
\hline 14 & Catechin & 6.74 & 289.0732 & $245,205,115$ & $152.6 \pm 3.9$ & n.d. & $2.5 \pm 0.2$ \\
\hline 15 & Quercetin 3-O-glucuronide & 8.38 & 477.0792 & 301 & $8.3 \pm 0.3$ & n.d. & n.d. \\
\hline 16 & Epicatechin & 8.60 & 289.0716 & 245,205 & $21.5 \pm 1.6$ & n.d. & n.d. \\
\hline 17 & Rutin & 15.85 & 609.1463 & 301 & $3.6 \pm 0.2$ & n.d. & n.d. \\
\hline 18 & Quercetin & 19.62 & 301.0461 & $179,151,119$ & $72.2 \pm 1.4$ & n.d. & n.d. \\
\hline \multicolumn{8}{|c|}{ Ellagitannins } \\
\hline 19 & Sanguisorbic acid dilactone & 12.89 & 469.005 & 315,301 & $173.2 \pm 2.7$ & n.d. & n.d. \\
\hline 20 & Ellagic acid & 14.54 & 300.9901 & 229,185 & $276.5 \pm 5.5$ & $44.1 \pm 2.3$ & n.d. \\
\hline
\end{tabular}

a DW, dry weight of dietary fibre; n.d., not detected.

${ }^{b}$ Results are expressed as mean \pm SD $(n=3)$.

were identified in its alkaline hydrolysate, reaching $469.9 \mathrm{mg} / 100 \mathrm{~g}$ DW. Phenolic acids accounted for $99 \%$ of the bound phenolic compounds released by alkaline treatment from wheat bran BP-IDF. Ferulic acid, which accounted for $88.2 \%$ of total phenolic acids, was the most representative among the eight identified phenolic acids. This result confirms the previous study carried out by Verma, Hucl, \& Chibbar (2009).
A

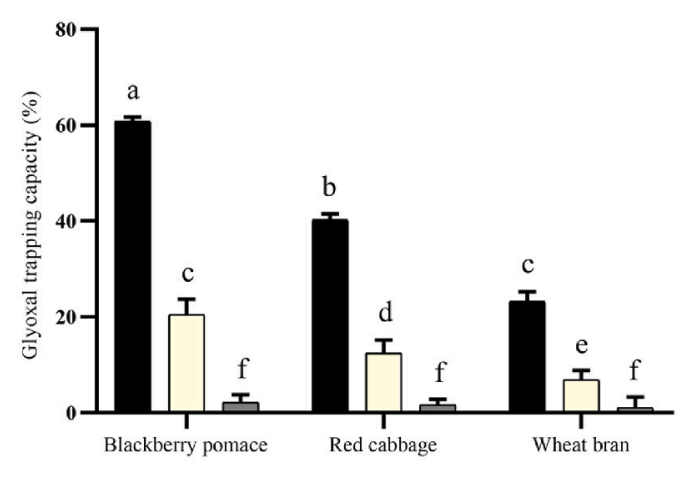

C

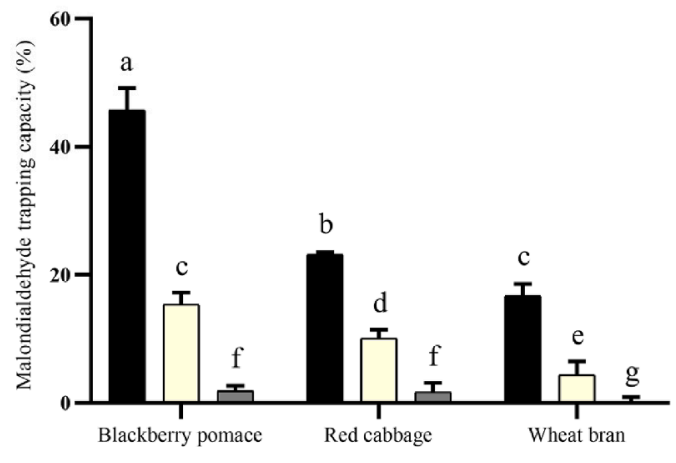

B

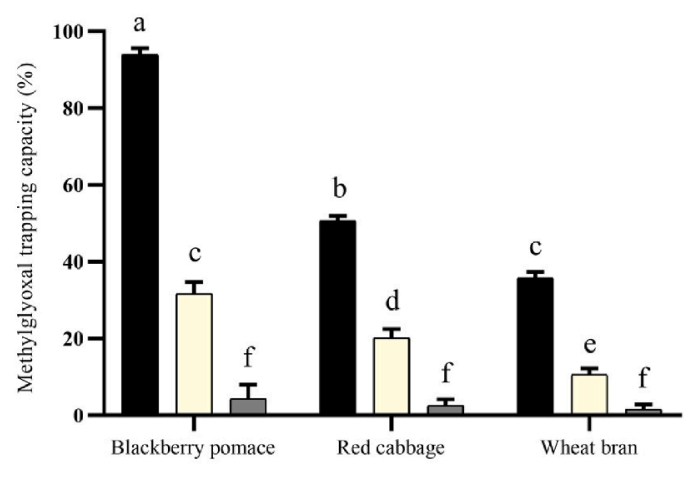

D

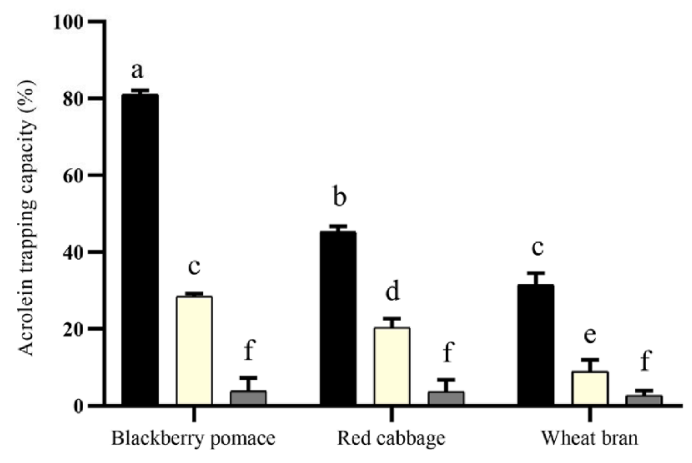

BP-IDF $\square$ Alkali-hydrolysed (4h) IDF

Alkali (4h)-sulfuric acid (20 h)-hydrolysed IDF

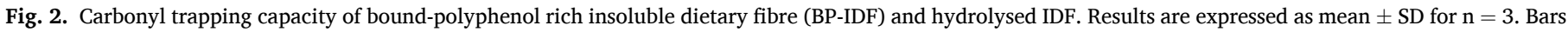
with the different letters indicate significant difference at $p<0.05$. 
3.2. Evaluation of the carbonyl trapping capacity of blackberry pomace, red cabbage and wheat bran BP-IDF and the major role of bound polyphenols

To investigate the physiological relevance of BP-IDF through carbonyl trapping capacity, BP-IDF was prepared at a concentration in line with the recommended daily intake of fibre, in the range of $25-38 \mathrm{~g}$ for adults (Quagliani \& Felt-Gunderson, 2017). Similarly, concentrations of the carbonyl compounds were based on the estimated dietary intake of unsaturated aldehyde and dicarbonyl compounds (Degen et al., 2012; Wang et al., 2008). As shown in Fig. 2, all the four tested carbonyls were effectively scavenged by blackberry pomace, red cabbage and wheat bran BP-IDF. The scavenging efficacy of three BP-IDF ranged from $16.7 \%$ to $45.7 \%$ for malondialdehyde, from $23.2 \%$ to $60.8 \%$ for glyoxal, and from $35.8 \%$ to $93.9 \%$ for methylglyoxal. Regarding acrolein, more than $81.2 \%, 45.3 \%$ and $31.5 \%$ of total amount were eliminated within 2 $\mathrm{h}$ by blackberry pomace, red cabbage and wheat bran BP-IDF, respectively. Concerning the contribution of BP-IDF to total carbonyl trapping capacity of plant foods, wheat bran BP-IDF accounts for more than $63.2 \%$ carbonyl trapping capacity of wheat bran whereas blackberry pomace and red cabbage BP-IDF showed relative low contribution, reaching 27.4 and $29.1 \%$, respectively (Fig. S4). After hydrolysis of BPIDF, the hydrolysed IDF showed much lower carbonyl trapping capacity compared to BP-IDF (Fig. 2). Alkaline treatment reduced more than $65 \%, 54 \%$ and $70 \%$ of scavenging efficacy for blackberry pomace, red cabbage and wheat bran BP-IDF, respectively, and nearly no carbonyl trapping capacity was retained after the further acidic hydrolysis. This behaviour is in agreement with our previous results showing that alkaline hydrolysis significantly reduces dicarbonyl trapping capacity of soluble coffee melanoidins (Zhang et al., 2019). In BP-IDF, bound polyphenols are linked to the cellular matrix by ester, ether as well as glycosidic bonds, which can be broken through alkaline and acidic hydrolysis, leading to a structural difference between BP-IDF and IDF (Pérez-Jiménez \& Torres, 2011). The decline of carbonyl trapping capacity can be attributed to the removal of bound phenolic compounds from BP-IDF (Fig. S5), indicating that the insoluble-bound polyphenols significantly contributed to the carbonyl trapping capacity of dietary fibre.

BP-IDF showed the highest trapping capacity for acrolein, followed by methylglyoxal, glyoxal and malondialdehyde. The reasons may be related to the different reactivity of carbonyl compounds towards polyphenols and to their arrangement in aqueous solution. The predominant form of malondialdehyde is enolate anion at $\mathrm{pH} 7.4$, which inhibits the nucleophilic reaction between malondialdehyde and bound polyphenols (Esterbauer, Schaur, \& Zollner, 1991). While in aqueous solution glyoxal exists mainly as the hydrated monomer, dimer and trimer, which may slow down the reaction rate of the trapping process for glyoxal by polyphenols (Zhu, Poojary, Andersen, \& Lund, 2019).

Differences observed in the trapping behaviour of BP-IDF may rise from the nature of bound polyphenols and the microstructure of dietary fibre. On one hand, blackberry pomace BP-IDF had a high amount of bound polyphenols including flavonoids, which are proven to be more reactive towards carbonyls compared to phenolic acids (Xie \& Chen, 2013). On the other hand, some of bound polyphenols are not located on the surface of fibre structure, which may strongly influence the interaction with free carbonyl compounds. The ability of bound polyphenols to scavenge carbonyl compounds paralleled previously published studies on antioxidant activity of dietary fibre: the antioxidant groups associated to insoluble fractions can quench free radicals present in aqueous solution through surface reactions, which are influenced by total surface area of the reacting solid (Gökmen et al., 2009). Dietary fibre remains up to about $24 \mathrm{~h}$ in the GI tract, in particular, in the lower gut lumen: this can increase the antioxidant activity of caecal content and the expression of endogenous antioxidant systems, thus reducing the tumour-promoting reactive oxygen species present in the colon (Pérez-Jiménez et al., 2013; Vitaglione et al., 2008). According to the concept of "antioxidant dietary fibre", our result indicated that BP-IDF from plant foods may help in eliminating RCS that are constantly formed in the GI tract.

\subsection{Influence of in vitro digestion on the carbonyl trapping capacity of BP-IDF}

To get insights into the effects of gastrointestinal digestion on the carbonyl trapping capacity, BP-IDF were subjected to the in vitro digestion process. Data summarized in Fig. 3, showed that after gastrointestinal digestion, three BP-IDF still exerted considerable carbonyl trapping capacity for all tested RCS, although a significant decrease was observed after $16 \mathrm{~h}$ of simulated colon digestion process, which is probably related to the release of bound phenolic compounds from polysaccharides (Papillo, Vitaglione, Graziani, Gokmen, \& Fogliano, 2014). The activity of BP-IDF was compared to free phenolic acids and flavonoids as caffeic acid and catechin according to their estimated dietary intake $(600 \mathrm{mg} /$ day and $400 \mathrm{mg} /$ day, respectively) (Bo' et al., 2019). The concentration of catechin used in this model system was close to that of total phenolic compounds in the alkaline extract of blackberry pomace BP-IDF (Table 1). The carbonyl scavenging of free catechin was lower than that of blackberry pomace BP-IDF but higher than that of red cabbage BP-IDF, while caffeic acid showed a similar carbonyl scavenging efficacy to wheat bran BP-IDF. The high carbonyl scavenging activity of blackberry pomace BP-IDF could be explained by the incomplete release of bound phenolic compounds by alkaline hydrolysis and the possible additive effects from different polyphenols (Pérez-Jiménez \& Torres, 2011; Shao et al., 2014). Although dietary polyphenols intake and their compositions are strongly affected by the diversity of eating habits among different geographical areas and populations, ranging from 60 to $600 \mathrm{mg}$ /day for flavonoids and from 100 to $729 \mathrm{mg}$ /day for phenolic acids, our results suggested that BP-IDF considerably contributed to the carbonyl scavenging within the GI tract compared to the dietary free polyphenols.

Food composition and physicochemical aspects of digesta and reactions occurring during digestion can further support the protective role of BP-IDF. Different dietary food components are digested together and some of them can sequester carbonyl compounds including free amino acids and small peptides (Jiang et al., 2019; Zhang et al., 2019). Most of digested proteins and some of free polyphenols are absorbed in small intestine whereas BP-IDF reach the colon with bound-polyphenols being nearly intact (Pérez-Jiménez et al., 2013). Moreover, antioxidant compounds bound to BP-IDF can be regenerated by free polyphenols present in the meal through synergistic antioxidant mechanism as observed for cereal products (Çelik et al., 2013). Regeneration mechanism underpins the potential beneficial effect of carbonyl scavenging capacity by BP-IDF on GI health: functional hydroxyl groups of BP-IDF are preserved and regenerated in the digestive system, thus maintaining an effective defence against reactive carbonyl electrophiles during their transit in the lower gut lumen. This evidence also opens a possibility for the utilization of BP-IDF in the design of functional foods with targeted prebiotic properties, supplying substrates for gut microbiota and protecting them against exogenous and endogenous carbonyl compounds. Recently, Brighina et al. (2021) reported that considerable amounts of 1,2-dicarbonyl compounds can pass through the in vitro gastrointestinal digestion phases and reduce probiotic species under the in vitro colonic fermentation conditions, promoting negative effects on the intestinal bacterial population and unwanted consequences on the digestion. In this respect the presence of polyphenols can be a valuable strategy in minimizing the toxicity of RCS for the gut microbiota, but further studies on the metabolites produced are needed to have a complete picture of the interconnection between polyphenols bound to dietary fibre and gut microbiota metabolism. 


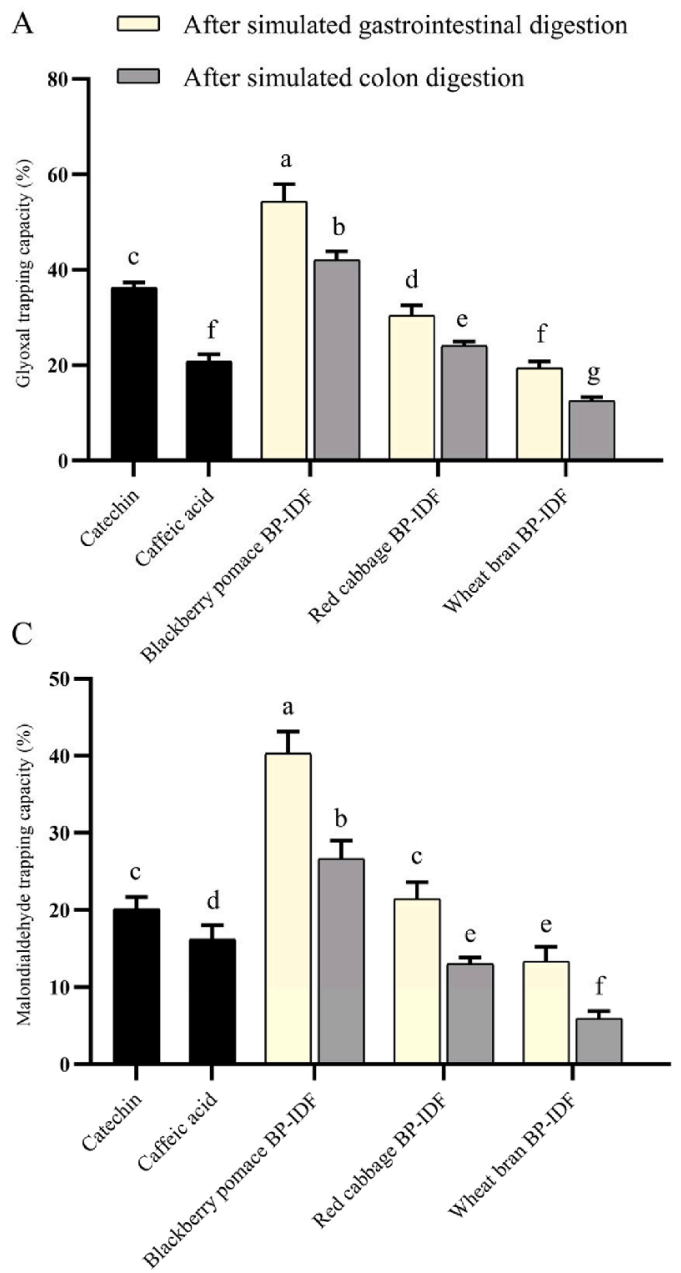

B

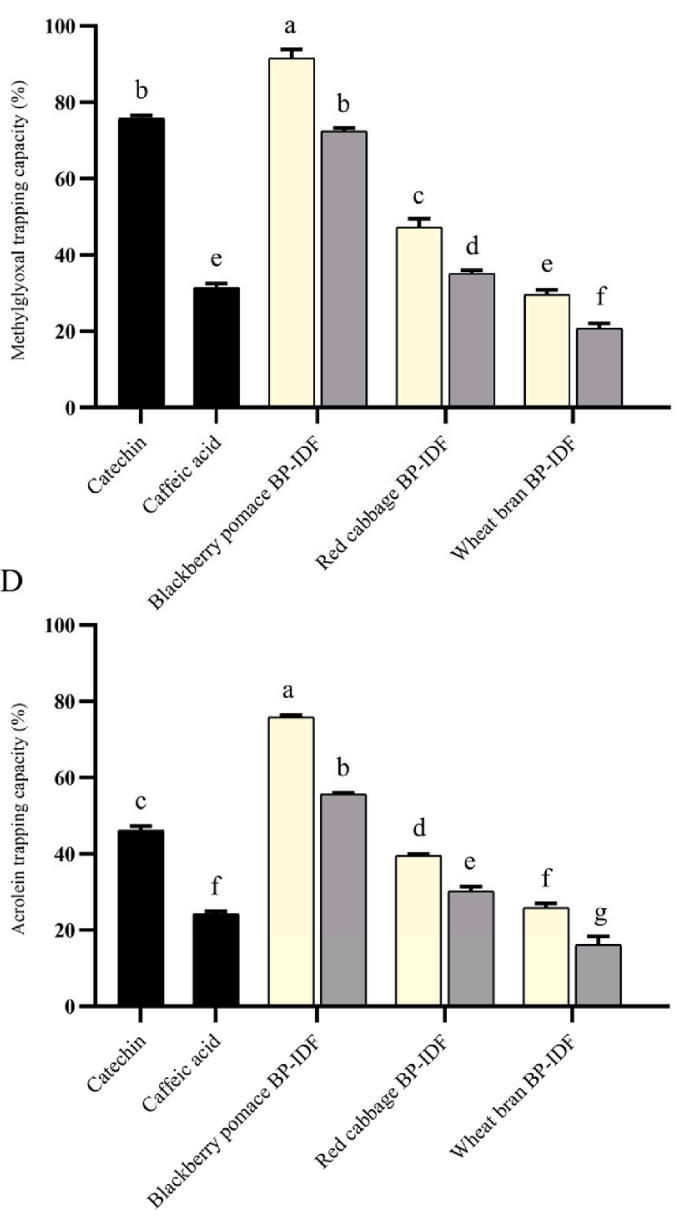

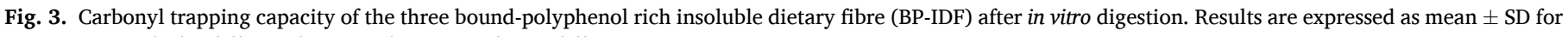
$\mathrm{n}=3$. Bars with the different letters indicate significant difference at $p<0.05$.

\subsection{Methylglyoxal adducts of gallic acid, catechin and quercetin bound to blackberry pomace BP-IDF}

Our group recently described the formation of melanoidins-bound caffeic acid-methylglyoxal adduct (Zhang et al., 2019). Therefore, we hypothesized that similarly to melanoidins, the formation of fibre-bound polyphenol-methylglyoxal adducts can occur also in the blackberry pomace BP-IDF which proved to be extremely effective in methylglyoxal scavenging (Fig. 2 panel B). We screened the methylglyoxal conjugates of main bound polyphenols, gallic acid, quercetin and catechin, in the alkaline extract of methylglyoxal-treated blackberry pomace BP-IDF by using tandem mass spectrometry. Furthermore, gallic acid, quercetin and catechin were also reacted with methylglyoxal in model systems to putatively identify gallic acid-, quercetin- and catechin-methylglyoxal adducts released from methylglyoxal-treated blackberry pomace BPIDF upon alkaline treatment. As highlighted in Fig. 4, five peaks with $m / z 241[\mathrm{M}-\mathrm{H}]^{-}, m / z 373[\mathrm{M}-\mathrm{H}]^{-}, m / z \quad 455[\mathrm{M}-\mathrm{H}]^{-}, \mathrm{m} / z 361$ $[\mathrm{M}-\mathrm{H}]^{-}$, and $m / z 433[\mathrm{M}-\mathrm{H}]^{-}$, respectively, were detected in blackberry pomace BP-IDF-methylglyoxal system after alkaline hydrolysis in SIM mode; each of them showed the same retention times with those from the model system of gallic acid, quercetin and catechin with methylglyoxal under simulated physiological conditions. The peak at 2.32 min exhibited the molecular ion at $\mathrm{m} / z 241[\mathrm{M}-\mathrm{H}]^{-}$and the fragment ions at $m / z 169$ and $m / z 125$, indicating the loss of methylglyoxal moiety and carbonyl group, respectively (Fig. 5A). This was in line with the fragmentation profile of mono-methylglyoxal-gallic acid conjugate formed in chemical reaction system of gallic acid and methylglyoxal, suggesting the release of mono-methylglyoxal-gallic acid adduct from methylglyoxal-treated blackberry pomace BP-IDF (de Falco et al., 2020).

The two peaks at 15.09 and $16.81 \mathrm{~min}$ in the chromatogram of blackberry pomace BP-IDF-methylglyoxal system shared the same retention time and fragmentation pattern with the mono-methylglyoxalquercetin at $m / z 373[\mathrm{M}-\mathrm{H}]^{-}$and di-methylglyoxal-quercetin at $m / z$ $455[\mathrm{M}-\mathrm{H}]^{-}$, in the chemical reaction system of quercetin and methylglyoxal (Fig. 5B). The fragment ions with $\mathrm{m} / \mathrm{z} 301[\mathrm{M}-72-\mathrm{H}]^{-}$and $\mathrm{m} / \mathrm{z}$ $205[\mathrm{M}-18-150-\mathrm{H}]^{-}$from the mono-methylglyoxal-quercetin adduct could match with a loss of one methylglyoxal and a loss of water molecule plus the typical breakdown of the $\mathrm{C}$ ring $(\mathrm{m} / \mathrm{z} 150)$, which was in agreement with the previous observation on the conjugation of methylglyoxal with quercetin at the C-6 or C-8 position of A ring (Li, Zheng, Sang, \& Lv, 2014). Similarly, the $\mathrm{MS}^{2}$ spectra of dimethylglyoxal-quercetin adduct had the same precursor ion having the daughter ion $m / z 277[\mathrm{M}-18-150-\mathrm{H}]^{-}$. Using a similar approach, we detected several products generated in the reaction of catechin and methylglyoxal. The two major peaks at 5.78 and $6.30 \mathrm{~min}$ were also observed in the alkaline extract of methylglyoxal-treated blackberry pomace BP-IDF, and they had the same retention time and $\mathrm{MS}^{2}$ spectrum (Fig. 5C). The peak with molecular ion $m / z \quad 361[\mathrm{M}-\mathrm{H}]^{-}$had the daughter ion of $m / z 289[\mathrm{M}-72-\mathrm{H}]^{-}$, formed upon the loss of the methylglyoxal moiety, and the daughter ion of $m / z 181[\mathrm{M}-180-\mathrm{H}]^{-}$, which was in line with the most abundant fragment ion of catechin $(\mathrm{m} / \mathrm{z}$ $\left.109[\mathrm{M}-180-\mathrm{H}]^{-}\right)$and could match with the typical cleavage of catechin on B ring (Yuzuak, Ballington, \& Xie, 2018). Therefore, it was 


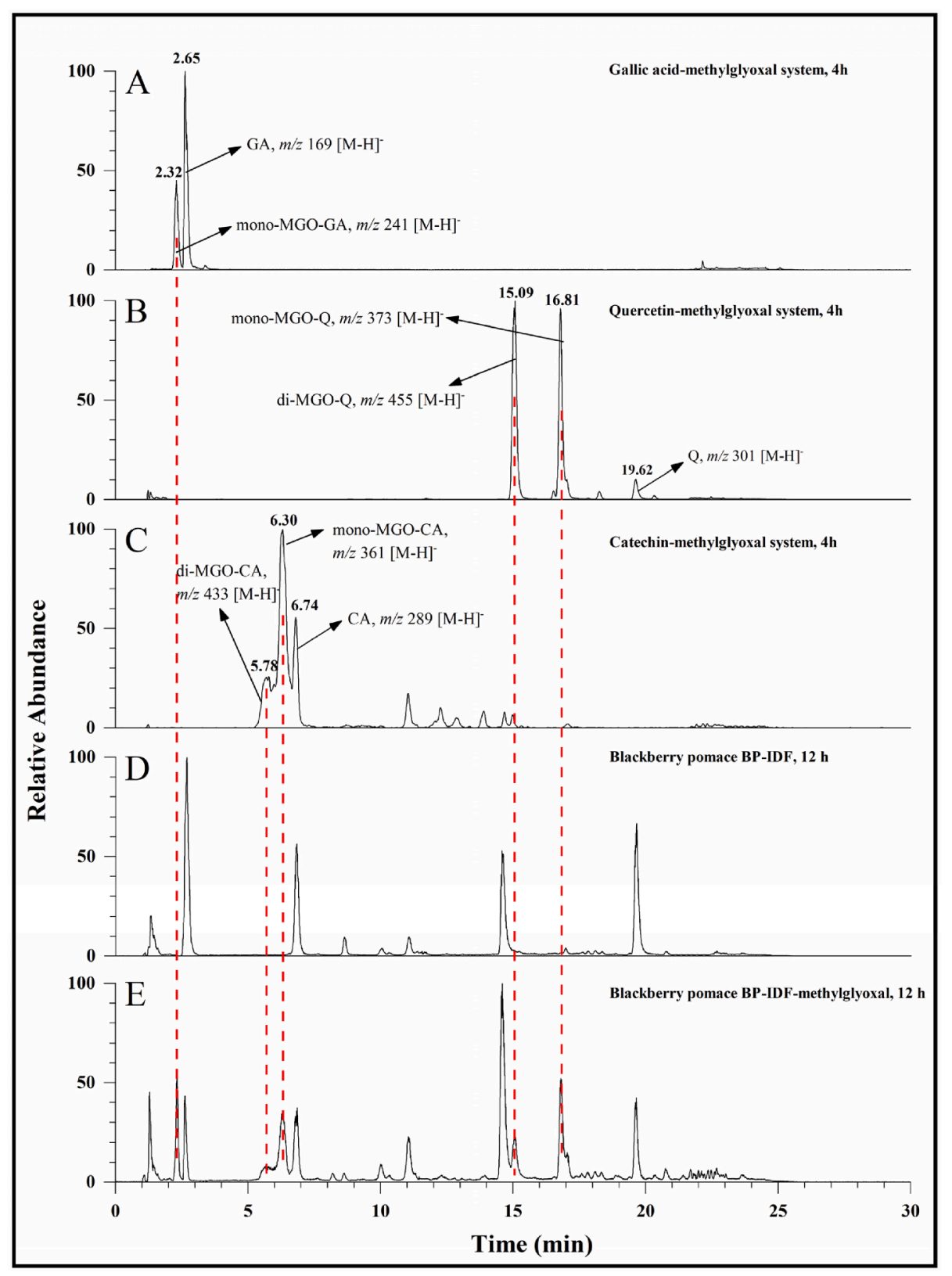

Fig. 4. The formation of methylglyoxal adducts of gallic acid, quercetin, catechin associated to blackberry pomace bound-polyphenol rich insoluble dietary fibre (BP-IDF). Total ion chromatograms of the samples collected from gallic acid- (A), quercetin(B) and catechin-methylglyoxal (C) chemical reaction systems after incubation at $37{ }^{\circ} \mathrm{C}$, and the samples collected from the alkaline extracts of blackberry pomace BP-IDF after the incubation with phosphate buffer (D, as negative control) or methylglyoxal (E) at $37^{\circ} \mathrm{C}$. identified as the mono-methylglyoxal-catechin adduct. In the $\mathrm{MS}^{2}$ spectra of $m / z 433[\mathrm{M}-\mathrm{H}]^{-}$, fragment ions at $m / z 361, m / z 289$, and $m / z$ 181 suggested the structure of mono-methylglyoxal-catechin, indicating that the peak at $5.78 \mathrm{~min}$ was the di-methylglyoxal-catechin adduct.

Along with methylglyoxal, glyoxal, acrolein and malondialdehyde adducts of gallic acid, quercetin and catechin were also investigated in the chemical reaction systems. Among all the model systems, monoglyoxal-quercetin, mono-glyoxal-catechin, mono-acrolein-gallic acid, mono-acrolein-quercetin and mono-acrolein-catechin were tentatively identified according to their molecular ions and $\mathrm{MS}^{2}$ spectra (Figures S6 and S7). The malondialdehyde adducts of three polyphenols were not detected although they showed considerable trapping capacity for malondialdehyde suggesting the primary adduct is not stable undergoing a quick degradation or intramolecular cyclization in our conditions.

Mass spectrometry results confirmed the formation of methylglyoxal adducts of polyphenols after the incubation of blackberry pomace BPIDF and methylglyoxal. Indeed, active sites of IDF-bound polyphenols can trap RCS through a nucleophilic reaction, as previously described for free polyphenols (Shao et al., 2014). Concerning BP-IDF as source of various types of polyphenols, different fibre-bound phenolic structures could enhance carbonyl trapping efficacy of each other because of additive and regeneration effects. This evidence indicated that insolublebound polyphenols can alternatively act as antioxidants and carbonyl scavengers in the gut.

\section{Conclusion}

Blackberry pomace, red cabbage and wheat bran BP-IDF effectively scavenged all the four RCS tested, namely glyoxal, methylglyoxal, malondialdehyde and acrolein. BP-IDF contributed to more than $21.9 \%$, $24.7 \%$ and $63.2 \%$ of total carbonyl trapping capacity of plant foods in the case of blackberry pomace, red cabbage and wheat bran, respectively. Our data showed that after in vitro digestion, there were still considerable carbonyl trapping capacity retained for all of three BP-IDF. The removal of fibre-bound polyphenols by alkaline and acidic hydrolysis reduced by up to $90 \%$ of carbonyl trapping capacity of BP-IDF. Finally, we detected methylglyoxal conjugates of polyphenols bound to blackberry pomace BP-IDF and the mono-acrolein adducts of gallic 


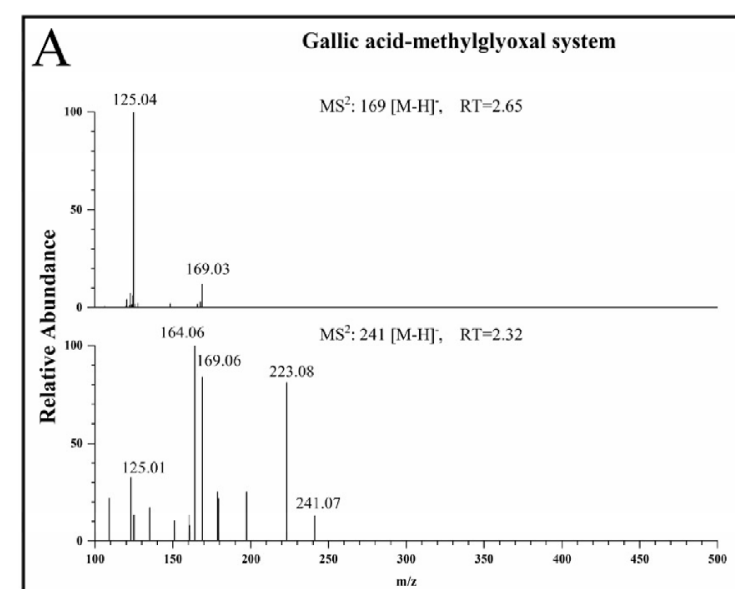

Blackberry pomace BP-IDF-methylglyoxal system
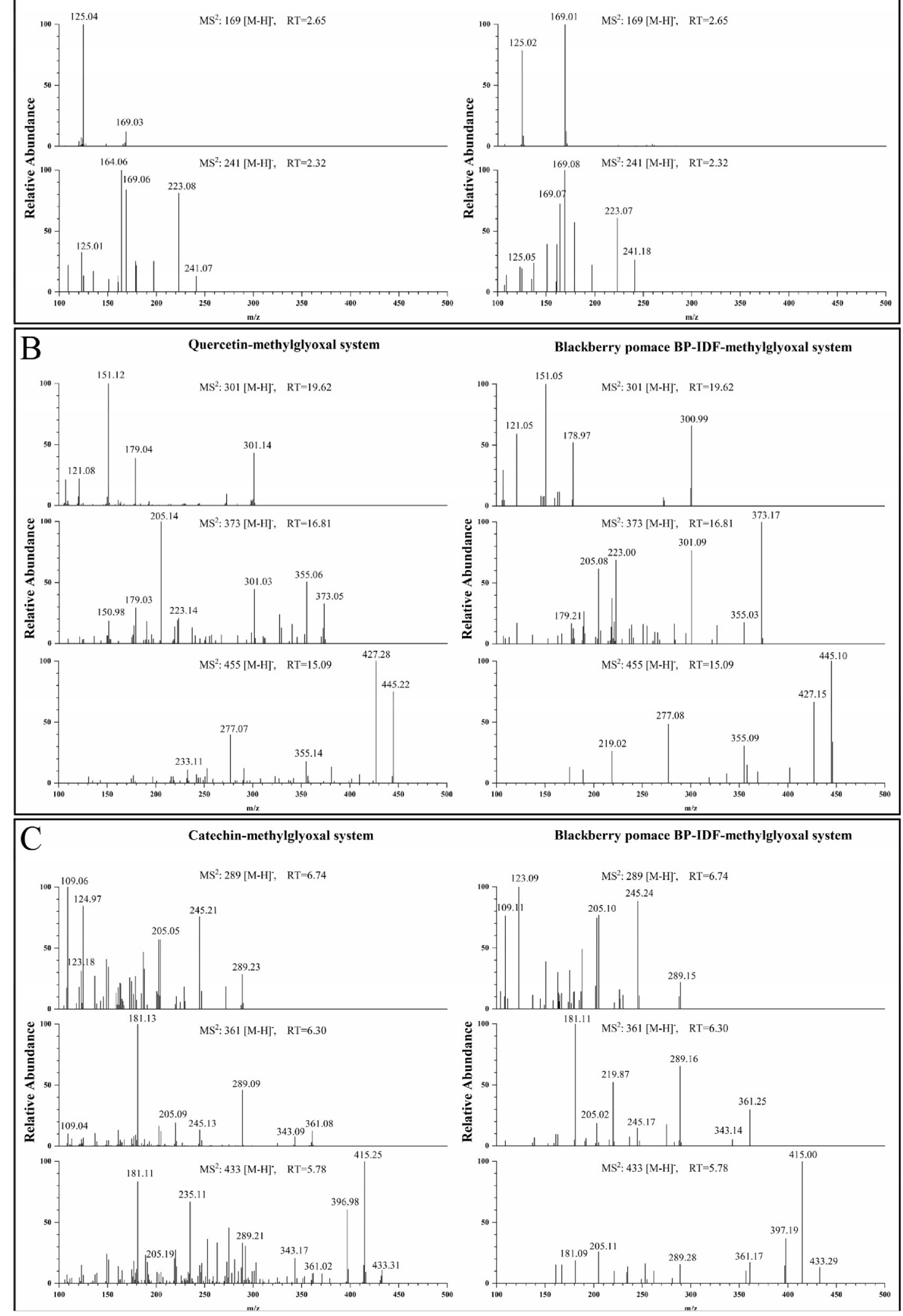

Fig. 5. A: ESI-MS ${ }^{2}$ spectra of gallic acid $\left(m / z 169\left[\mathrm{M}-\mathrm{H}^{-}\right]\right)$and mono-methylglyoxal-gallic acid $\left(\mathrm{m} / \mathrm{z} 241\left[\mathrm{M}-\mathrm{H}^{-}\right]\right)$; B: ESI-MS ${ }^{2}$ spectra of quercetin $(m / z 301$ $\left.\left[\mathrm{M}-\mathrm{H}^{-}\right]\right)$, mono-methylglyoxal-quercetin $\left(\mathrm{m} / z 373\left[\mathrm{M}-\mathrm{H}^{-}\right]\right)$and di-methylglyoxal-quercetin $\left(\mathrm{m} / z 455\left[\mathrm{M}-\mathrm{H}^{-}\right]\right)$; C: ESI-MS ${ }^{2}$ spectra of catechin $\left(m / z 289\left[\mathrm{M}-\mathrm{H}^{-}\right]\right)$, mono-methylglyoxal-catechin $\left(\mathrm{m} / z 361\left[\mathrm{M}-\mathrm{H}^{-}\right]\right)$and di-methylglyoxal-catechin $\left(\mathrm{m} / z\right.$ $\left.433\left[\mathrm{M}-\mathrm{H}^{-}\right]\right)$. 
acid, quercetin and catechin, suggesting the ability of insoluble-bound polyphenols to trap RCS under simulated physiological conditions. Looking at these results with a wider physiological prospective, the carbonyl trapping capacity of BP-IDF should be considered for its potential benefits inside the GI tract. The quantification of the polyphenolRCS adduct can be used to have indications about the role of dietary intervention in the reduction of oxidative stress in the colon.

\section{CRediT authorship contribution statement}

Hao Zhang: Conceptualization, Investigation, Methodology, Formal analysis, Data curation, Resources, Visualization, Writing - original draft. Antonio Dario Troise: Methodology, Formal analysis, Visualization, Supervision, Writing - review \& editing. Yajing Qi: Methodology, Formal analysis, Visualization, Resources. Gangcheng Wu: Formal analysis, Software. Hui Zhang: Project administration, Conceptualization, Supervision, Funding acquisition, Writing - review \& editing. Vincenzo Fogliano: Conceptualization, Supervision, Writing - review \& editing.

\section{Declaration of Competing Interest}

The authors declare that they have no known competing financial interests or personal relationships that could have appeared to influence the work reported in this paper.

\section{Acknowledgment}

We gratefully acknowledge financial support from China Scholarship Council.

\section{Appendix A. Supplementary data}

Supplementary data to this article can be found online at https://doi. org/10.1016/j.foodchem.2021.129018.

\section{References:}

Arranz, S., \& Saura Calixto, F. (2010). Analysis of polyphenols in cereals may be improved performing acidic hydrolysis: A study in wheat flour and wheat bran and cereals of the diet. Journal of Cereal Science, 51(3), 313-318.

Ayoub, M., de Camargo, A. C., \& Shahidi, F. (2016). Antioxidants and bioactivities of free, esterified and insoluble-bound phenolics from berry seed meals. Food Chemistry, 197, 221-232.

Bo' Bernardi Marino Porrini Tucci Guglielmetti Cherubini Carrieri Kirkup Kroon ZamoraRos Liberona Andres-Lacueva Riso Systematic Review on Polyphenol Intake and Health Outcomes: Is there Sufficient Evidence to Define a Health-Promoting Polyphenol-Rich Dietary Pattern? Nutrients 1161355 10.3390/nu11061355 https://www.mdpi.com/2072-6643/11/6/1355.

Brighina, S., Poveda Turrado, C., Restuccia, C., Walton, G., Fallico, B., OrunaConcha, M. J., \& Arena, E. (2021). Detrimental effect on the gut microbiota of 1,2dicarbonyl compounds after in vitro gastro-intestinal and fermentative digestion. Food Chemistry, 341, 128237. https://doi.org/10.1016/j.foodchem.2020.128237.

Celik, E. E., Gökmen, V., \& Fogliano, V. (2013). Soluble antioxidant compounds regenerate the antioxidants bound to insoluble parts of foods. Journal of Agricultural and Food Chemistry, 61(43), 10329-10334.

de Falco, B., Petridis, A., Paramasivan, P., Troise, A. D., Scaloni, A., Deeni, Y., Stephens, W. E., \& Fiore, A. (2020). Reducing toxic reactive carbonyl species in ecigarette emissions: Testing a harm-reduction strategy based on dicarbonyl trapping. RSC Advances, 10(36), 21535-21544.

Degen, J., Hellwig, M., \& Henle, T. (2012). 1,2-Dicarbonyl compounds in commonly consumed foods. Journal of Agricultural and Food Chemistry, 60(28), 7071-7079.

Esterbauer, H., Schaur, R. J., \& Zollner, H. (1991). Chemistry and biochemistry of 4hydroxynonenal, malonaldehyde and related aldehydes. Free Radical Biology and Medicine, 11(1), 81-128.

Ferguson, G. P., Tötemeyer, S., MacLean, M. J., \& Booth, I. R. (1998). Methylglyoxal production in bacteria: Suicide or survival? Archives of Microbiology, 170(4), 209-218.

Gökmen, V., Serpen, A., \& Fogliano, V. (2009). Direct measurement of the total antioxidant capacity of foods: The 'QUENCHER' approach. Trends in Food Science \& Technology, 20(6-7), 278-288.

Goñi, I., Díaz-Rubio, M. E., Pérez-Jiménez, J., \& Saura-Calixto, F. (2009). Towards an updated methodology for measurement of dietary fiber, including associated polyphenols, in food and beverages. Food Research International, 42(7), 840-846.
Hammer, J., Pruckmayer, M., Bergmann, H., Kletter, K., \& Gangl, A. (1997). The distal colon provides reserve storage capacity during colonic fluid overload. Gut, 41(5), 658-663.

Hamzalıoğlu, A., \& Gökmen, V. (2016). Investigations on the reactions of $\alpha$-dicarbonyl compounds with amino acids and proteins during in vitro digestion of biscuits. Food Function, 7(6), 2544-2550.

Jiang, K., Huang, C., Jiao, R., Bai, W., Zheng, J., \& Ou, S. (2019). Adducts formed during protein digestion decreased the toxicity of five carbonyl compounds against Caco-2 cells. Journal of Hazardous Materials, 363, 26-33.

Li, X., Zheng, T., Sang, S., \& Lv, L. (2014). Quercetin inhibits advanced glycation end product formation by trapping methylglyoxal and glyoxal. Journal of Agricultural and Food Chemistry, 62(50), 12152-12158.

Liu, S., Jia, M., Chen, J., Wan, H., Dong, R., Nie, S., Xie, M., \& Yu, Q. (2019). Removal of bound polyphenols and its effect on antioxidant and prebiotics properties of carrot dietary fiber. Food Hydrocolloids, 93, 284-292.

Macierzyński, J., Sójka, M., Kosmala, M., \& Karlińska, E. (2020). Transformation of oligomeric ellagitannins, typical for rubus and fragaria genus, during strong acid hydrolysis. Journal of Agricultural and Food Chemistry, 68(31), 8212-8222.

Mizgier, P., Kucharska, A. Z., Sokół-Łętowska, A., Kolniak-Ostek, J., Kidoń, M., \& Fecka, I. (2016). Characterization of phenolic compounds and antioxidant and antiinflammatory properties of red cabbage and purple carrot extracts. Journal of Functional Foods, 21, 133-146.

Nardini, M., Cirillo, E., Natella, F., Mencarelli, D., Comisso, A., \& Scaccini, C. (2002). Detection of bound phenolic acids: Prevention by ascorbic acid and ethylenediaminetetraacetic acid of degradation of phenolic acids during alkaline hydrolysis. Food Chemistry, 79(1), 119-124. https://doi.org/10.1016/S0308-8146 (02)00213-3.

Papillo, V. A., Vitaglione, P., Graziani, G., Gokmen, V., \& Fogliano, V. (2014). Release of antioxidant capacity from five plant foods during a multistep enzymatic digestion protocol. Journal of Agricultural and Food Chemistry, 62(18), 4119-4126.

Pérez-Jiménez, J., Díaz-Rubio, M. E., \& Saura-Calixto, F. (2013). Non-extractable polyphenols, a major dietary antioxidant: Occurrence, metabolic fate and health effects. Nutrition Research Reviews, 26(2), 118-129.

Pérez-Jiménez, J., Elena Díaz-Rubio, M., \& Saura-Calixto, F. (2015). Contribution of macromolecular antioxidants to dietary antioxidant capacity: A study in the spanish mediterranean diet. Plant Foods for Human Nutrition, 70(4), 365-370.

Pérez-Jiménez, J., \& Torres, J. L. (2011). Analysis of nonextractable phenolic compounds in foods: The current state of the art. Journal of Agricultural and Food Chemistry, 59 (24), 12713-12724.

Pérez-Ramírez, I. F., Reynoso-Camacho, R., Saura-Calixto, F., \& Pérez-Jiménez, J. (2018). Comprehensive characterization of extractable and nonextractable phenolic compounds by high-performance liquid chromatography-electrospray ionization-quadrupole time-of-flight of a grape/pomegranate pomace dietary supplement. Journal of Agricultural and Food Chemistry, 66(3), 661-673.

Quagliani, D., \& Felt-Gunderson, P. (2017). Closing America's Fiber Intake Gap: Communication Strategies From a Food and Fiber Summit. American Journal of Lifestyle Medicine, 11(1), 80-85.

Rabbani, N., \& Thornalley, P. J. (2015). Dicarbonyl stress in cell and tissue dysfunction contributing to ageing and disease. Biochemical and Biophysical Research Communications, 458(2), 221-226.

Rašić, I., Rašić, A., Akšamija, G., \& Radović, S. (2018). The relationship between serum level of malondialdehyde and progression of colorectal cancer. Acta Clinica Croatica, 57(3), 411-416. https://doi.org/10.20471/acc.2018.57.03.02.

Saura-Calixto, F. (1998). Antioxidant dietary fiber product: A new concept and a potential food ingredient. Journal of Agricultural and Food Chemistry, 46(10), 4303-4306. https://doi.org/10.1021/jf9803841.

Shao, X.i., Chen, H., Zhu, Y., Sedighi, R., Ho, C.-T., \& Sang, S. (2014). Essential structural requirements and additive effects for flavonoids to scavenge methylglyoxal. Journal of Agricultural and Food Chemistry, 62(14), 3202-3210.

Thornalley, P. J. (1985). Monosaccharide autoxidation in health and disease. Environmental Health Perspectives, 64, 297-307.

Verma, B., Hucl, P., \& Chibbar, R. N. (2009). Phenolic acid composition and antioxidant capacity of acid and alkali hydrolysed wheat bran fractions. Food Chemistry, 116(4), 947-954.

Vitaglione, P., Napolitano, A., \& Fogliano, V. (2008). Cereal dietary fibre: A natural functional ingredient to deliver phenolic compounds into the gut. Trends in Food Science \& Technology, 19(9), 451-463.

Wang, G.-W., Guo, Y., Vondriska, T. M., Zhang, J., Zhang, S.u., Tsai, L. L., Zong, N. C., Bolli, R., Bhatnagar, A., \& Prabhu, S. D. (2008). Acrolein consumption exacerbates myocardial ischemic injury and blocks nitric oxide-induced PKCE signaling and cardioprotection. Journal of Molecular and Cellular Cardiology, 44(6), 1016-1022.

Wang, Z., Li, S., Cao, Y.u., Tian, X., Zeng, R., Liao, D.-F., \& Cao, D. (2016). Oxidative stress and carbonyl lesions in ulcerative colitis and associated colorectal cancer. Oxidative Medicine and Cellular Longevity, 2016, 1-15.

Xie, Y., \& Chen, X. (2013). Structures required of polyphenols for inhibiting advanced glycation end products formation. Current Drug Metabolism, 14(4), 414-431. https:// doi.org/10.2174/1389200211314040005.

S. Yuzuak J. Ballington D.-Y. Xie HPLC-qTOF-MS/MS-Based Profiling of Flavan-3-ols and Dimeric Proanthocyanidins in Berries of Two Muscadine Grape Hybrids FLH 13-11 and FLH 17-66 Metabolites 8457 10.3390/metabo8040057 http://www.mdpi. com/2218-1989/8/4/57.

Zhang, H., Zhang, H., Troise, A. D., \& Fogliano, V. (2019). Melanoidins from coffee, cocoa, and bread are able to scavenge $\alpha$-dicarbonyl compounds under simulated physiological conditions. J. Agric. Food Chem., 67(39), 10921-10929. 
Zhang, J., Sturla, S., Lacroix, C., Schwab, C., \& Johnson, E. A. (2018). Gut microbial glycerol metabolism as an endogenous acrolein source. MBio, 9(1). https://doi.org/ 10.1128/mBio.01947-17.

Zhang, S., Zhao, Y., Ohland, C., Jobin, C., \& Sang, S. (2019). Microbiota facilitates the formation of the aminated metabolite of green tea polyphenol (-)-epigallocatechin-3- gallate which trap deleterious reactive endogenous metabolites. Free Radical Biology and Medicine, 131, 332-344.

Zhu, H., Poojary, M. M., Andersen, M. L., \& Lund, M. N. (2019). Effect of pH on the reaction between naringenin and methylglyoxal: A kinetic study. Food Chemistry, 298, 125086. https://doi.org/10.1016/j.foodchem.2019.125086. 